\title{
MUSIC ENHANCES THE EFFECT OF POSITIVE EMOTIONAL STATES ON SALIVARY IgA
}

\author{
ROLLIN MCCRATY, MA, MIKE ATKINSON AND GLEN REIN PhD \\ Institute of HeartMath, Boulder Creek, CA, USA \\ ALAN D. WATKINS, MBBS \\ Department of University Medicine, Southampton General Hospital, Southampton, UK
}

\begin{abstract}
SUMMARY
This study examines the effects of music and positive emotional states on autonomic and immune functions in normal, healthy individuals. Autonomic activity was assessed using power spectral density analysis of heart rate variability, and salivary IgA was used as a marker of immunity. The effects of rock, new age and designer music were examined alone, and in conjunction with a self-induced positive emotional state. The results indicate that only the designer music and the self-induced state of appreciation produced a significant increase in autonomic activity and salivary IgA (S-IgA). In addition, the combination of the designer music and the self-induced appreciation produced a much greater immunoenhancement than either of these two conditions alone. We conclude that music can be designed to enhance the beneficial effects of positive emotional states on immunity, and that this effect may be mediated by the autonomic nervous system. These data raise the tantalizing possibility that music and emotional self-management may have significant health benefits in a variety of clinical situations in which there is immunosuppression and autonomic imbalance.
\end{abstract}

KEY WORDS - heart rate variability; S-IgA; music; autonomic nervous system; emotion; self-regulation

It is well recognized that mental and emotional activity can alter autonomic nervous system (ANS) function. ${ }^{1,2}$ Similarly the ANS has been shown to profoundly affect the cardiovascular, ${ }^{3}$ neuroendocrine $^{4}$ and immune functions. ${ }^{5}$ It has been suggested that the immunosuppression known to occur during negative emotional states, such as bereavement, depression, ${ }^{6,7}$ or anger, ${ }^{8}$ and the immunoenhancement associated with positive emotional states ${ }^{8,9}$ may be mediated, in part, by the ANS. ${ }^{10}$ It is also well recognized that music can alter mood and emotional states. ${ }^{11-14}$ However, few studies have examined the effects of music on the immune system, ${ }^{15,16}$ and none have determined whether these effects are mediated by the ANS.

We investigated the effects of music on autonomic activity and immunity using power spectral density (PSD) analysis of heart rate variability (HRV). Changes in HRV have been used to characterize a number of psychological illnesses including major depression and panic disorders, ${ }^{17,18}$ in addition to its use as a non-invasive

Address for correspondence: $\mathrm{Mr} \mathrm{R}$. McCraty, Institute of HeartMath, 14700 W. Park Ave, Boulder Creek, CA 95006, USA. Tel: (408) 338-8727. Fax: (408) 338-1182. test of integrated neurocardiac function. ${ }^{19}$ Thus the mathematical transformation of heart rate variability into power spectral density provides a potential link between perception, emotional states, cardiovascular function and immunity. The interaction of mood, immunity and autonomic function has been highlighted by a number of studies showing that anger and hostility increase sympathetic activity ${ }^{1,20}$ and suppress immunity, ${ }^{8,21}$ while positive emotional states, such as appreciation, enhance parasympathetic activity ${ }^{2}$ and boost immunity. 8,22

Scientific investigation of the use of music as a therapeutic modality began after World War II when its positive effects on emotionally disturbed, shell-shocked individuals were observed. Music therapy research has since demonstrated beneficial effects on the cardiovascular system, ${ }^{23}$ pain perception, ${ }^{24,25}$ stress $^{26,27}$ and endocrine activity. ${ }^{28}$ Music therapy has been shown to increase S-IgA in hospitalized children after a single session, ${ }^{16}$ or after six weeks of ongoing therapy. ${ }^{29}$ Anxiety associated with the stress of surgery was reduced after listening to music, ${ }^{26,30}$ and music has been shown to decrease anxiety levels even in the absence of a specific stressor. ${ }^{31-33}$ Music has not only been used to promote relaxation ${ }^{14,34-37}$ and 
improve mood, ${ }^{12,38}$ but has also been employed in a wide variety of other medical settings. ${ }^{39}$ The major difficulty in interpreting these data is that music was frequently used in conjunction with either relaxation therapy or guided imagery. Therefore it remains unclear to what extent music, by itself, can modify autonomic or immunological parameters. We have previously demonstrated that self-induced positive emotional states can alter sympathovagal balance ${ }^{2}$ and increase S-IgA. ${ }^{8}$ In this study we assessed the effects of three different types of music including a new type of music called 'designer music', which is reported by the composer to have a balancing effect on one's mental and emotional states. Specifically, we investigated the effects of a single music session on autonomic function and S-IgA and whether 'designer music' could enhance the autonomic and immunological effects of positive emotional states in a synergistic manner.

\section{METHODOLOGY}

\section{Subjects}

All 10 individuals (four male and six female) used in this study were in good health and free from respiratory symptoms, colds and headaches. The age of the subjects varied between 27 and $53 \mathrm{yr}$ (mean 41). All individuals maintained the same work schedule, sleep cycle, social environment and diet. None of the subjects were currently taking prescription drugs and all refrained from smoking, exercising and eating or drinking anything except water for at least 8 hours prior to each testing period.

\section{Experimental Design}

The autonomic and immunological effects of three categories of music (rock, new age and designer) were assessed in a crossover design in which the subjects acted as their own controls. Each category of music was presented for 15 minutes on separate days with a 2-day washout period between each session. Subjects were instructed as follows: 'Sit quietly and listen to the music, without distracting one another. Listen in a casual, relaxed way, but try to avoid falling asleep. Allow the music to take you wherever it takes you in regards to your moods, feelings, memories, sensations, etc.' In order to determine whether the designer music enhanced the autonomic shifts previously observed during positive emotional states, subjects were asked to consciously focus on generating and maintaining a feeling of heartfocused appreciation for someone or something as best they could throughout the 15-minute period. In addition, autonomic and immunological functions were assessed during the self-induced positive emotional state in the absence of music, and during a control session in which no music was played.

\section{Electrophysiological data}

All electrophysiological and immunological recording was commenced at 10 am to minimize diurnal variations. Subjects were seated in straight, highback chairs to minimize postural changes, and fitted with $\mathrm{Ag} / \mathrm{AgCL}$ disposable ECG electrodes. The positive electrode was located on the left side of the chest over the sixth rib and the reference was placed in the right supraclavicular fossa. Grass model 7P4 ECG amplifiers were used. ECG measurements were recorded throughout the entire 15-minute baseline period, and throughout the 15 minutes of music that followed. This was repeated for each music category. Heart rate (HR), shortterm HRV and PSD measures were calculated for the baseline and active listening periods during each session. For the purposes of analysis the baseline and active listening periods were reduced to 5-minute epochs and the HRV and PSD variables for each 5-minute period were averaged to produce a mean baseline and active listening score. Five subjects were recorded per session over 12 sessions. Prior to each session subjects were asked to refrain from talking, falling asleep, exaggerated body movements and intentionally altering their respiration. Subjects were carefully monitored to ensure there were no significant respiratory or postural changes during the session.

\section{HRV Analysis}

The short-term HRV signal was in the form of an $\mathrm{R}-\mathrm{R}$ interval tachogram. PSD was obtained from the mathematical transformation of a series of consecutive but discrete $\mathrm{R}-\mathrm{R}$ intervals taken from the ECG signal, which was sampled at $256 \mathrm{~Hz}$. All data were digitized by a Bio Pac 16-bit digitizer and software system. Analyses of HRV, fast Fourier transforms (FFT), PSD (calculated as $\left.(\mathrm{BPM})^{2} / \mathrm{Hz}\right)$ and time domain measurements were performed using DADiSP/32 digital signal processing software. 
The power spectrum was divided into three major frequency ranges (LF, MF and HF) as previously described. ${ }^{40}$ The integral of the power spectrum within each region was calculated. The $L F$ region $(0.01-0.05 \mathrm{~Hz})$ is primarily considered a measure of sympathetic activity with a minor parasympathetic component. ${ }^{40,41}$ In contrast, the $\mathrm{HF}$ region $(0.15-0.5 \mathrm{~Hz})$ is associated with respiratory sinus arrhythmia and is almost exclusively due to parasympathetic activity. ${ }^{40}$ Power in the $\mathrm{MF}$ region is a mixture of sympathetic and parasympathetic activity, but predominantly the latter. ${ }^{40}$ The MF region $(0.05-0.15 \mathrm{~Hz})$ has also been used as an indirect measure of baroreceptor activity which controls blood pressure. ${ }^{42}$

\section{$S-\operatorname{Ig} A$ Determinations}

Unstimulated, whole saliva samples were collected over a 4-minute period as previously described. ${ }^{43}$ Samples were collected immediately before and after each 15-minute music listening period and frozen at $-200^{\circ} \mathrm{C}$ in liquid nitrogen.

Salivary $\operatorname{IgA}$ concentrations were determined using the single radial immunodiffusion method as previously described ${ }^{44}$ Briefly, $5 \mu$ l aliquots of saliva were diluted $1: 2(\mathrm{v} / \mathrm{v})$ with phosphate buffered saline (Fisher, San Francisco, CA) and loaded into 14 well plates (The Binding Site, San Diego, CA) coated with monospecific sheep antihuman S-IgA (Binding Site, San Diego, CA). The 14 well plates were simultaneously loaded with $15 \mu \mathrm{l}$ of purified human serum S-IgA standard (Binding Site, San Diego, CA), and incubated at $20^{\circ} \mathrm{C}$ for 72 hours. The diameter of the precipitation ring was measured using an $8 \times$ ocular micrometer to an accuracy of $0.1 \mathrm{~mm}$. All measurements were made blind, by two separate observers, and the average of two separate readings by each observer was calculated. Interobserver variance ranged from 0 to $10 \%$. S-IgA concentration values were estimated by comparison to the standard curve values. All S-IgA concentrations are expressed as $\mathrm{mg} / 1$.

\section{The music}

The effects of rock and new age music were compared to a new type of music described as 'designer music' ${ }^{45,46}$ The designer music utilized in this study was titled 'Heart Zones'. The composer specifically designed this music 'to facilitate mental and emotional balance and create a calm yet energetic alertness' ${ }^{47}$ The rock and new age music was chosen for its popularity as rated by the Billboard music charts. The mixed selection of rock music consisted of the following songs: 'Start the Car' by Jude Cole, 'Tall Cool One' by Robert Plant, 'Pearl Necklace' by ZZ Top and 'Addicted to that Rush' by Mr. Big. The new age music consisted of the following songs: 'Dance with a Stranger' by Yanni, 'Kathleen's Song' by Ray Lynch and 'Oasis' by Kitaro. All music selections were played on a high quality stereo system, at a level of $70 \mathrm{~dB}$ at head height at the focal point of the stereo field.

\section{Self-induced positive emotional states}

Self-induced positive emotional states were generated by instructing the subjects to: 'First think of someone or something you feel deep, sincere appreciation towards. Do your best to actually feel appreciation and maintain that feeling for the next 15 minutes; if you find your mind wandering or lose your focus, simply shift your attention back to the feeling of appreciation.'

\section{Statistical analysis}

The Friedman two-way ANOVA was used to compare baseline values between sessions for all variables. Comparisons of raw baseline data with those obtained during the three different categories of music were performed using the Wilcoxon signed rank sum test $(t)$, utilizing the sum of the ranks for positive and negative differences for each group. Wilcoxon $p$-values were taken from the table of critical values for the Wilcoxon signed rank test. Pre and post music S-IgA values were also analysed for significance using the two-tailed Wilcoxon sign-ranked test. Salivary IgA results are expressed as a percentage change relative to baseline values.

\section{RESULTS}

\section{$H R V$ analysis}

We demonstrated an increase in total autonomic activity (LF $+\mathrm{MF}+\mathrm{HF}$ ) during the 'Heart Zones' music session $(p<0.02)$ (Fig. 1A), the self-induced positive emotional state $(p<0.01)$ (Fig. 1B) and during the session combining the self-induced state of appreciation and 'Heart Zones' music $(p=0.02)$ (Fig. 1C). In contrast, there was no change in total 

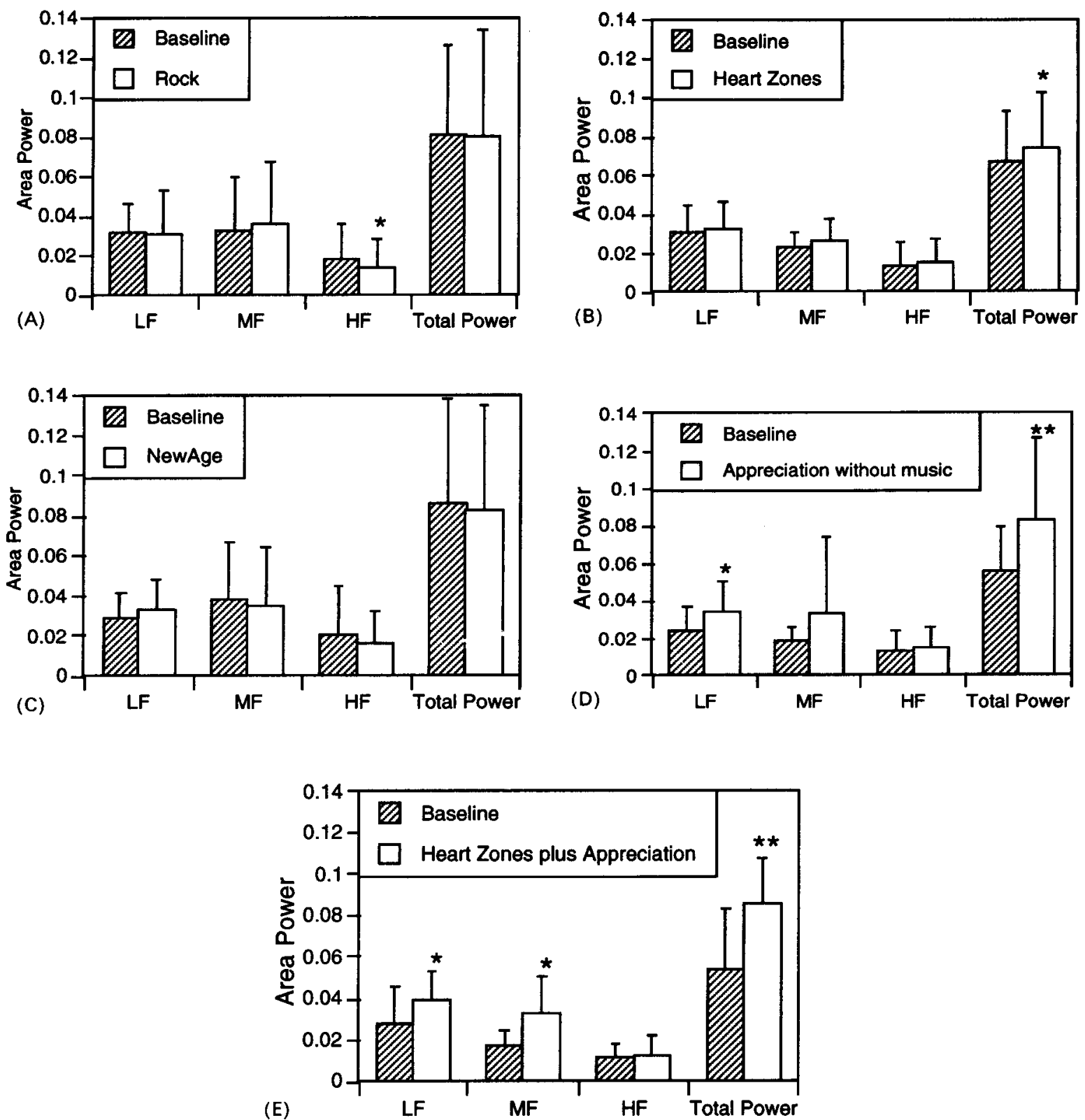

Fig. IA-E-The graphs in Figs 1A-1C illustrate the autonomic variables LF, MF, HF and total power during the baseline and music periods for each category of music, in $1 \mathrm{D}$ during self-induced appreciation, and in $1 \mathrm{E}$ while listening to the 'Heart Zones' music during self-induced appreciation. ${ }^{*}$, Significance $p<0.05 ;{ }^{* *}, p<0.01$

autonomic activity during the new age or rock music (Figs. 1D and 1E). There was also an increase in the mean HR standard deviation (HRSD) during the self-induced appreciation session $(p=0.02)$ and the session combining appreciation and 'Heart Zones' music $(p=0.02)$.
In addition, there was an increase in LF power during appreciation $(p<0.05)$ and also during appreciation while listening to 'Heart Zones' $(p=0.05)$. Appreciation alone produced no effects on the MF power whereas the addition of 'Heart Zones' music to self-induced appreciation 
Table 1-Baseline and intervention scores and SDs of heart rate variability measures while listening to the rock music

\begin{tabular}{lcccccc}
\hline Variable & $\begin{array}{c}\text { Pretest } \\
\text { mean }\end{array}$ & $\begin{array}{c}\text { Pretest } \\
\text { SD }\end{array}$ & $\begin{array}{c}\text { Post-test } \\
\text { mean }\end{array}$ & $\begin{array}{c}\text { Post-test } \\
\text { SD }\end{array}$ & $\begin{array}{c}\text { Wilcoxon } \\
t\end{array}$ & $p$ \\
\hline LF & 0.031 & 0.015 & 0.031 & 0.022 & 24 & NS \\
MF & 0.032 & 0.027 & 0.036 & 0.033 & 24 & NS \\
HF & 0.018 & 0.017 & 0.014 & 0.014 & 7 & $<0.05$ \\
Total pwr & 0.082 & 0.044 & 0.081 & 0.053 & 26 & NS \\
HR & 65.268 & 5.948 & 65.900 & 6.023 & 22 & NS \\
HRSD & 3.676 & 0.891 & 3.601 & 1.117 & 21 & NS \\
\hline
\end{tabular}

Table 2-Baseline and intervention scores and SDs of heart rate variability measures while listening to the 'Heart Zones' music

\begin{tabular}{lcccccc}
\hline Variable & $\begin{array}{c}\text { Pretest } \\
\text { mean }\end{array}$ & $\begin{array}{c}\text { Pretest } \\
\text { SD }\end{array}$ & $\begin{array}{c}\text { Post-test } \\
\text { mean }\end{array}$ & $\begin{array}{c}\text { Post-test } \\
\text { SD }\end{array}$ & $\begin{array}{c}\text { Wilcoxon } \\
t\end{array}$ & $p$ \\
\hline LF & 0.030 & 0.014 & 0.032 & 0.014 & 16 & NS \\
MF & 0.023 & 0.008 & 0.026 & 0.011 & 9 & NS \\
HF & 0.014 & 0.012 & 0.015 & 0.013 & 11 & NS \\
Total pwr & 0.067 & 0.026 & 0.074 & 0.030 & 4 & $<0.02$ \\
HR & 67.896 & 4.916 & 69.240 & 6.886 & 14 & NS \\
HRSD & 3.457 & 0.792 & 3.379 & 0.881 & 23 & NS \\
\hline
\end{tabular}

Table 3-Baseline and intervention scores and SDs of heart rate variability measures while listening to the new age music

\begin{tabular}{lcccccc}
\hline Variable & $\begin{array}{c}\text { Pretest } \\
\text { mean }\end{array}$ & $\begin{array}{c}\text { Pretest } \\
\text { SD }\end{array}$ & $\begin{array}{c}\text { Post-test } \\
\text { mean }\end{array}$ & $\begin{array}{c}\text { Post-test } \\
\text { SD }\end{array}$ & $\begin{array}{c}\text { Wilcoxon } \\
t\end{array}$ & $p$ \\
\hline LF & 0.029 & 0.012 & 0.033 & 0.015 & 19 & NS \\
MF & 0.037 & 0.029 & 0.035 & 0.029 & 19 & NS \\
HF & 0.020 & 0.025 & 0.016 & 0.016 & 15 & NS \\
Total pwr & 0.087 & 0.051 & 0.083 & 0.053 & 22 & NS \\
HR & 63.300 & 5.098 & 63.465 & 4.420 & 19 & NS \\
HRSD & 3.779 & 0.958 & 3.822 & 1.061 & 25 & NS \\
\hline
\end{tabular}

produced a significant increase in MF power $(p=0.02)$. We also demonstrated a decrease in HF power during the rock music session $(p<0.05)$. There were no significant differences in any variables between the baseline and the no music control session. The raw data values are shown for each category of music and the control and appreciation only intervention in Tables 1-6.

\section{Salivary $\operatorname{Ig} A$}

There were no changes in S-IgA concentrations during the no music control, rock or new age music sessions. In contrast, S-IgA increased by 55 per cent $(p<0.01)$ when listening to the 'Heart Zones' music alone. Similarly, self-induced appreciation alone also produced a significant increase in S-IgA of 50 per cent $(p<0.05)$. Self-induced appreciation while simultaneously listening to 'Heart Zones', produced a substantially greater (141 per cent) increase in S-IgA than either 'Heart Zones' or appreciation alone $(p<0.01)$.

\section{DISCUSSION}

The relationship between positive and negative emotional states and immunity is complex and 
Table 4-Baseline and intervention scores and SDs of heart rate variability measures while feeling appreciation only

\begin{tabular}{lcccccc}
\hline Variable & $\begin{array}{c}\text { Pretest } \\
\text { mean }\end{array}$ & $\begin{array}{c}\text { Pretest } \\
\text { SD }\end{array}$ & $\begin{array}{c}\text { Post-test } \\
\text { mean }\end{array}$ & $\begin{array}{c}\text { Post-test } \\
\text { SD }\end{array}$ & $\begin{array}{c}\text { Wilcoxon } \\
t\end{array}$ & $p$ \\
\hline LF & 0.024 & 0.012 & 0.034 & 0.016 & 7 & $<0.05$ \\
MF & 0.019 & 0.006 & 0.034 & 0.040 & 12 & NS \\
HF & 0.013 & 0.011 & 0.015 & 0.011 & 17 & NS \\
Total pwr & 0.056 & 0.024 & 0.083 & 0.044 & 0 & $<0.01$ \\
HR & 67.728 & 7.515 & 68.393 & 7.436 & 16 & NS \\
HRSD & 3.227 & 0.771 & 3.759 & 0.954 & 5 & 0.02 \\
\hline
\end{tabular}

Table 5-Baseline and intervention scores and SDs of heart rate variability measures while feeling appreciation and listening to the 'Heart Zones' music

\begin{tabular}{lcccccc}
\hline Variable & $\begin{array}{c}\text { Pretest } \\
\text { mean }\end{array}$ & $\begin{array}{c}\text { Pretest } \\
\text { SD }\end{array}$ & $\begin{array}{c}\text { Post-test } \\
\text { mean }\end{array}$ & $\begin{array}{c}\text { Post-test } \\
\text { SD }\end{array}$ & $\begin{array}{c}\text { Wilcoxon } \\
t\end{array}$ & $p$ \\
\hline LF & 0.028 & 0.018 & 0.040 & 0.013 & 8 & 0.05 \\
MF & 0.017 & 0.007 & 0.033 & 0.018 & 3 & 0.01 \\
HF & 0.011 & 0.006 & 0.013 & 0.009 & 26 & NS \\
Total pwr & 0.054 & 0.029 & 0.085 & 0.023 & 5 & 0.02 \\
HR & 68.888 & 9.019 & 70.198 & 8.434 & 14 & NS \\
HRSD & 3.219 & 0.889 & 3.914 & 0.656 & 5 & 0.02 \\
\hline
\end{tabular}

Table 6-Heart rate variability measures and SDs during the no music control. Subjects sat quietly for the same time period as when listening to the music

\begin{tabular}{lcccccc}
\hline Variable & $\begin{array}{c}\text { Pretest } \\
\text { mean }\end{array}$ & $\begin{array}{c}\text { Pretest } \\
\text { SD }\end{array}$ & $\begin{array}{c}\text { Post-test } \\
\text { mean }\end{array}$ & $\begin{array}{c}\text { Post-test } \\
\text { SD }\end{array}$ & $\begin{array}{c}\text { Wilcoxon } \\
t\end{array}$ & $p$ \\
\hline LF & 0.029 & 0.015 & 0.033 & 0.024 & 22 & NS \\
MF & 0.027 & 0.018 & 0.031 & 0.014 & 19 & NS \\
HF & 0.016 & 0.015 & 0.014 & 0.012 & 21 & NS \\
Total pwr & 0.071 & 0.036 & 0.078 & 0.038 & 13 & NS \\
HR & 66.391 & 6.407 & 66.294 & 6.633 & 27 & NS \\
HRSD & 3.506 & 0.865 & 3.639 & 0.968 & 11 & NS \\
\hline
\end{tabular}

depends on a number of factors including how the emotional state was induced and the immune parameter measured. ${ }^{8,48} \mathrm{We}$ have previously shown that self-induced care and compassion produced an increase in S-IgA nearly five times greater than watching a videotape of Mother Teresa, ${ }^{8}$ a technique previously used by McClelland to modulate immunity ${ }^{22}$. In the present study, the self-induced state of appreciation also produced a substantial increase in $\mathrm{S}-\operatorname{IgA}$, and this increase was significantly enhanced by simultaneously listening to designer music. Several studies have reported the enhancing effects of music on visualization, ${ }^{15,24,28,49}$ psychotherapy ${ }^{50}$ and self- induced emotional states. ${ }^{51}$ For example, music has been shown to enhance the effect of imagery on $\mathrm{S}-\mathrm{IgA}$, whereas music in the absence of imagery had no effect. ${ }^{16}$ In contrast to the above study, we demonstrated that designer music alone produced a significant increase in $\mathrm{S}-\operatorname{IgA}$, whereas the other forms of contemporary music did not.

The mechanisms mediating the immunoenhancing effects of music and positive emotional states on S-IgA are unknown. However, we provide evidence that links the ANS to this process. Specifically, we demonstrated an increase in autonomic spectral power in all experimental conditions where there was an increase in S-IgA. 


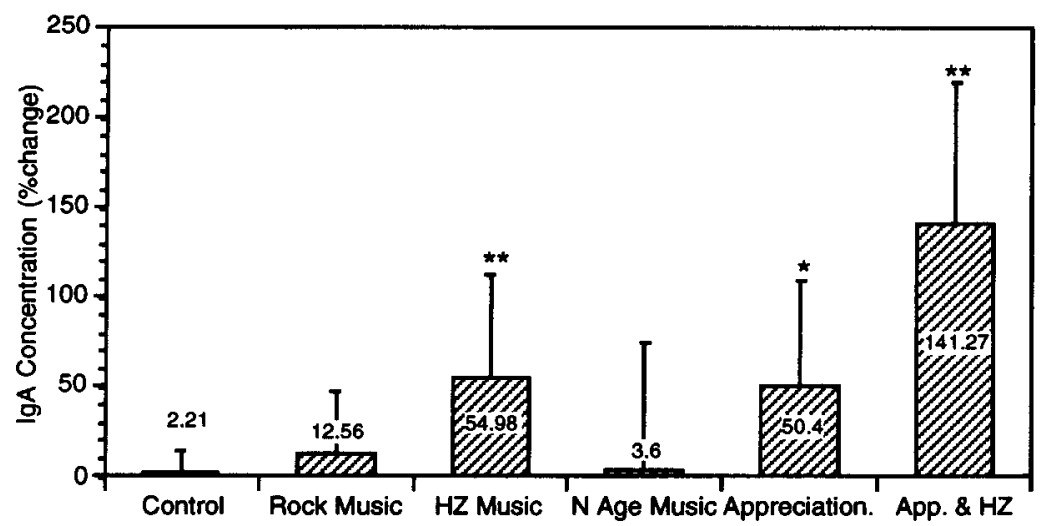

Fig. 2-Comparison of changes in S-IgA levels after listening to 15 minutes of music or a no music control. Values represent per cent change $( \pm S D)$ relative to baseline levels. Saliva was collected from each individual before and immediately after listening to the music. ${ }^{*}$, Significance $p<0.05 ;{ }^{* *}, p<0.01$

The salivary glands are known to receive a rich autonomic innervation; ${ }^{52}$ however, whether the secretion of $\mathrm{S}-\mathrm{IgA}$ is predominantly under the control of sympathetic or parasympathetic innervation is not yet clear.

We have previously shown that positive emotional states reduce sympathetic activity and increase parasympathetic activity, as reflected by an increase in MF and HF power. ${ }^{2}$ In the present study, we demonstrated that the positive emotional state of appreciation produced an increase in total autonomic power, but the increase in MF power just failed to reach significance. The failure to demonstrate an increase in parasympathetic activity may be due to the fact that the technique used in this study to produce the positive emotional states was not as refined as that used previously, and the subjects were not as well practised in self-inducing positive emotional states as those used in the previous study. Nevertheless, we were able to demonstrate that the combination of listening to 'Heart Zones' music while in a state of appreciation did produce a significant increase in parasympathetic activity, and this was associated with an increase in S-IgA. Taken together, these data suggest that increased parasympathetic activity may promote S-IgA secretion. This is in keeping with previous research suggesting that stressful environments reduce $\mathrm{S}-\operatorname{IgA}, 21,53$ while positive situations enhance $\mathrm{S}-\operatorname{IgA} .^{8,22}$

While new age music is believed to promote a relaxed state, we were unable to demonstrate any changes in autonomic function or immunity with the selections chosen in this study. In sharp contrast, we provide evidence that the immunoenhancing effects of the designer music used in this study were mediated by the autonomic nervous system, since listening to the 'Heart Zones' music alone produced an increase in total autonomic power. Although a number of studies have demonstrated that music can alter autonomic function, ${ }^{14,34,54,55}$ this is, we believe, the first demonstration that the autonomic effects of music can potentiate the immunoenhancing effects of positive emotional states.

In conclusion, this study provides support for the view that music affects autonomic function and that music can be designed to enhance the beneficial effects of positive emotional states. The immunoenhancing effects seen here may be brokered by the parasympathetic nervous system, as reflected in the increase in MF power during the combination of designer music and appreciation. Increased MF power has been shown to be a marker of baroreceptor activity and therefore the use of designer music, which enhances MF power, may prove to be an important adjunct in the management of hypertension.

A larger study involving over 200 subjects is now in progress to determine whether the autonomic effects of music, which we believe mediate the observed immunoenhancement, are secondary to the induction of a positive emotional state. Whether the beneficial effects on autonomic function and immunity of positive emotional states and designer music can be extended to clinical health benefits is a tantalizing possibility that warrants further investigation. 


\section{REFERENCES}

1. Kamada, T., Miyake, S., Kumashiro, M., Monou, $H$. and Inoue, $K$. Power spectral analysis of heart rate variability in type As and type Bs during mental workload. Psychosom. Med. 1992; 54: 462-470.

2. McCraty, R., Atkinson, M., Tiller, W. A., Rein, G. and Watkins, A. The effects of emotions on short term power spectrum analysis of heart rate variability. Am. J. Cardiol. 1995; 76: 1089-1093.

3. Sinha, R., Lovallo, W. R. and Parsons, O. A. Cardiovascular differentiation of emotions. Psychosom. Med. 1992; 54(4): 422-435.

4. Lovallo, W. R., Pincomb, G. A., Brackett, D. J. and Wilson, M. F. Heart rate reactivity as a predictor of neuroendocrine responses to aversive and appetitive challenges. Psychosom. Med. 1990; 52: 17-26.

5. Ader, R., Felten, D. L. and Cohen, N.(Eds). Psychoneuroimmunology, 2nd edn. Academic Press, San Diego, 1991.

6. He, M. A prospective controlled study of psychosomatic and immunologic changes in recently bereaved people. Chinese J. Neurol-Psychiat. 1993; 24: $90-93$.

7. Shekelle, R. B., Raynor, W. J., Ostfeld, A. M., Garron, D. C., Bieliauskas, L., Liu, S. C., Maliza, C. and Paul, O. Psychological depression and 17-year risk of death from cancer. Psychosom. Med. 1981; 43: $117-125$.

8. Rein, G. and McCraty, R. M. Effects of positive and negative emotions on salivary IgA. J. Adv. Med. 1995; 8(2): 87-105.

9. Dillon, K. M., Minchoff, B. and Baker, K. H. Positive emotional states and enhancement of the immune system. Int. J. Psych. Med. 1986; 15(1): $13-16$.

10. Watkins, A. D. Perceptions, emotions and immunity: an integrated homeostatic network. Quart. $J$. Med. 1995; 88: 283-294.

11. Altschuler, I. A psychiatrist's experience with music as a therapeutic agent. In: Music and Medicine. Schullian, D. and Schoen, M. (Eds) Books for Libraries Press, New York, 1948, pp. 250-275.

12. Lenton, S. R. and Martin, P. R. The contribution of music vs instructions in the musical mood induction procedure. Behav. Res. Ther. 1991; 29(6): 623-625.

13. Palakanis, K. C., DeNobile, J. W., Sweeney, W. B. and Blankenship, C. L. Effect of music therapy on state anxiety in patients undergoing flexible sigmoidoscopy. Dis. Colon Rectum 1994; 37: $478-481$.

14. Updike, P. and Charles, D. Music Rx: Physiological and emotional responses to taped music programs of preoperative patients awaiting plastic surgery. Ann. of Plast. Surg. 1987; 9(1): 29-33.

15. Rider, M. S. and Achterberg, J. Effect of musicassisted imagery on neutrophils and lymphocytes. Biofeedback Self-Regulation 1989; 14(\#3): 247-257.
16. Rider, M. Imagery, improvisation, and immunity. Psychotherapy 1990; 17: 211-216.

17. Yeragani, V. K., Pohl, R., Berger, R., Balon, R., Ramesh, C., Glitz, D., Srinivasan, K. and Weinberg, P. Decreased HRV in panic disorder patients: A study of power-spectral analysis of heart rate. Psychiat. Res. 1993; 46: 89-13.

18. Yeragani, V. K., Pohl, R., Balon, R., Ramesh, C., Glitz, D., Jung, I. and Sherwood, P. Heart rate variability in patients with major depression. Psychiat. Res. 1991: 37: 35-46.

19. Ori, Z., Monir, G., Weiss, J., Sayhouni, X. and Singer, D. H. Heart rate variability frequency domain analysis. Amb. Electrocardio. 1992; 10(3): $499-537$.

20. Sloan, R. P., Shapiro, P. A., Bigger, J. T., Bagiella, E., Steinman, R. C. and Gorman, J. M. Cardiac autonomic control and hostility in healthy subjects. Am. J. Cardiol. 1994; 74: 298-300.

21. McClelland, D., Floor, E. and Davidson, R. Stressed power motivation, sympathetic activation, immune function and illness. J. Hum. Stress 1980; 6: 11-19.

22. McClelland, D. C. and Kirshnit, C. The effects of motivational arousal through films on salivary immunoglobulin A. Psychol. Health 1988; 2: 31-52.

23. Updike, P. Music therapy results for ICU patients. Dimens. of Crit. Care Nurs. 1990; 9(1): 39-45.

24. Rider, M. S. Treating chronic disease and pain with music-mediated imagery. Arts Pyschother. 1987; 14: $113-120$.

25. Whipple, B. and Glynn, N. J. Quantification of the effects of listening to music as a non-invasive method of pain control. Schol. Inq. Nurs. Prac. Int. J. 1992; 6: $43-62$.

26. Chetta, H. D. The effect of music and desensitization on preoperative anxiety in children. $J$. Mus. Ther. 1981; 18: 74-87.

27. Thayer, J. and Levenson, R. Effects of music on psychophysiological responses to a stressful film. Psychomusicology 1983; 3: 44-52.

28. Rider, M., Floyd, J. and Kirkpatric, J. The effect of music imagery and relaxation on adrenal corticosteroids and the re-entrainment of circadian rhythms. J. Mus. Ther. 1985; 22(1): 46-58.

29. Rider, M. S., Achterberg, J., Lawlis, G. F., Goven, A., Toledo, R. and Butler, J. R. Effect of immune system imagery on secretory IgA. Biofeedback Self Regulation 1990; 15: 317-333.

30. Heitz, L., Symrent, T. and Scamman, F. Effect of music therapy in the postanesthesia care unit: Nursing intervention. J. Post Anesthes. Nurs. 1992; 7: $22-31$.

31. Kaempf, G. and Amodei, M. The effect of music on anxiety. AORN J. 1989; 50(1): 112-118.

32. Gross, J. and Swartz, R. The effects of music therapy on anxiety in chronically ill patients. Mus. Ther. 1982; 2: 43-52. 
33. Stoudenmire, J. A comparison of music relaxation training and music in the reduction of state and trait anxiety. J. Clin. Psych. 1975; 31: 490-492.

34. Kibler, V. E. and Rider, M. Effects of progressive muscle relaxation and music on stress as measured by finger temperature response. J. Clin. Psych. 1983; 39(2): $213-215$.

35. Davis, W. and Thaut, $M$. The influence of preferred relaxing music on measures of state anxiety, relaxation and physiological responses. J. Mus. Ther. 1989; 26(4): $168-187$.

36. Thaut, $M$. The influence of music therapy interventions on self-rated changes in relaxation, affect and thought in psychiatric prisoner-patients. $J$. Mus. Ther. 1989; 26(3): 155-166.

37. Guzzetta, C. E. Effects of relaxation and music therapy on patients in a coronary care unit with presumptive acute myocardial infarction. Heart Lung 1989; 18: 606-616.

38. Rehm, L. Mood, pleasant events and unpleasant events: Two pilot studies. J. Consult. Clin. Psychol. 1978; 46: 854-859.

39. Aldridge, D. The music of the body: Music therapy in medical settings. Advances 1993; 9(1): 17-35.

40. Akselrod, S., Gordon, D., Ubel, F. A., Shannon, D. C., Barger, A. C. and Conen, R. J. Power spectrum analysis of heart rate fluctuation: $A$ quantitative probe of beat-to-beat cardiovascular control. Science 1981; 213(10): 220-222.

41. Pagani, M., Lombardi, F. and Guzzette, S. Power spectral analysis of heart rate and arterial pressure variabilities as a marker of sympatho-vagal interaction in man and conscious dog. Circ. Res. 1986; 59: $178-184$.

42. Robbe, H. W. J., Mulder, L. J. M., Ruddel, H., Langewitz, W. A., Veldman, J. B. P. and Mulder, G. Assessment of baroreceptor reflex sensitivity by means of spectral analysis. Hyperten. 1987; 10: $538-543$.
43. Kerr, A. The Physiological Regulation of Salivary Secretions in Man. Pergamon Press, Oxford 1961.

44. Mancini, G., Carbonara, A. and Hermans, J. Immunochemical quantitation of antigens by single radial immunodiffusion. Immunochem. 1965; 2: 235-239.

45. Bowden, M. Composer creates 'designer music' as therapeutic relaxation tool. The Sun, Baltimore, 1993; May 18, D1.

46. Bernstein, A. Outlook-eye on the '90s. US News World Rep. 1992; 113: 24.

47. Childre, D. L. Heart Zones. Planetary Publications, Boulder Creek, CA: 1991.

48. Futterman, A. D., Kemeny, M. E., Shapiro, D., Polonsky, W. and Fahey, J. L. Immunological variability associated with experimentally-induced positive and negative affective states. Psychol. Med. 1992 (22): 231-238.

49. Bonny, H. L. The Role of Taped Music Programs in the GIM Process. ICM Books, Baltimore, 1978.

50. Hanser, S. B. and Thompson, L. W. Effects of a music therapy strategy on depressed older adults. J. Gerontol. 1994; 49(6): 265-269.

51. Spies, K., Hesse, F. W. and Ueffing, E. Experimental induction of emotional states: Does addition of music improve self disclosure? Z. Exp. Angew. Psychol. 1991; 38(2): 321-342.

52. Mathison, R., Davison, J. S. and Befus, A. D. Neuroendocrine regulation of inflammation and tissue repair by submandibular gland factors. Immunol. Today 1994; 15(11): 527-532.

53. Jemmott, J. B. and Magloire, K. Academic stress, social support and secretory immunoglobulin $\mathrm{A}$. J. Person. Soc. Psychol. 1988; 55: 803-810.

54. Allen, K. and Blascovich, J. Effects of music on cardiovascular reactivity among surgeons. JAMA $1994 ; 272(1): 882-884$.

55. Goldstein, A. Thrills in response to music and other stimuli. Physiol. Psychol. 1980; 8(1): 126-129. 